\title{
Detection of subpigment epithelial neovascularisation in cases of retinal pigment epithelial detachments: a review of the Moorfields treatment trial
}

\author{
S Pagliarini`, M J Barondes†, I H Chisholm, A M Hamilton, A C Bird
}

\begin{abstract}
The entry angiograms of 42 eyes with detachment of the retinal pigment epithelium in a treatment trial of laser photocoagulation were reviewed in a masked fashion by three observers in order to assess the possible presence of subpigment epithelial neovascularisation. Vascularity or avascularity was designated with reference to a list of clues believed to imply the presence of subpigment epithelial neovascularisation. As a predictor of outcome the initial assessment achieved a sensitivity and specificity of $77 \%$ and $82 \%$ respectively. Despite notable parity of the degree of sensitivity and specificity among the three observers, full agreement on the initial assessments was reached in only 23 eyes $(55 \%), 10$ with vascular and 13 with avascular outcome. Of these, only one eye which developed new vessels after 4 years had an outcome which differed from that predicted by classification of the entry angiograms.
\end{abstract}

Retinal pigment epithelial detachment (PED) as a consequence of age-related maculopathy represents an important cause of irreversible visual loss in the elderly..$^{1-4}$ Some PEDs occur without demonstrable neovascularisation in the subpigment epithelial space while in others fluorescein angiography shows new vessels or there is indirect evidence of their presence. ${ }^{2-8}$ Histological studies imply that new vessels from the choroid may have already invaded the space between the detached pigment epithelium and Bruch's membrane even when angiography has failed to demonstrate their presence. ${ }^{910}$ Uncertainty as to the presence and extent of subpigment epithelial blood vessels accounts, in part, for differences in the reported natural history of PEDs ${ }^{45811-22}$ and for their unpredictable response to treatment. ${ }^{811623-28}$ It has now become apparent that if blood vessels are not clearly shown by fluorescein angiography certain characteristics of the lesion such as irregular punctate hyperfluorescence, ${ }^{3571829}$ flattening or indentation of the smooth convex border (notches), ${ }^{5029}$ hyperfluorescence beyond the edge of the lesion at the site of a notch, ${ }^{5730}$ and early pronounced hyperfluorescence at the edge of the PED may imply their presence.

A treatment trial of laser photocoagulation for this disorder was suspended after 18 months when results showed an excess of visual loss in treated eyes when compared with controls. ${ }^{26}$ Entry criteria had excluded patients with clear evidence of choroidal neovascularisation such as haemorrhage, exudate, regional masking not related to hyperpigmentation, progressive subpigment epithelial hyperfluorescence (hot spots) and a manifest leaking subretinal capillary complex. Because of the more recently described indicators of neovascularisation, there is considerable doubt as to the validity of the conclusions drawn from the original therapeutic study as it may apply to 'avascular' PEDs. This has prompted us to review the original angiograms, and to reclassify them in the light of the changing criteria for the detection of new vessels and to compare the revised designation with the subsequent outcome of disease. The influence of the reclassification upon the conclusions as to therapy are described elsewhere. $^{31}$

\section{Materials and methods}

We reviewed the entry fluorescein angiograms from the treatment trial ${ }^{24}$ for signs of subpigment epithelial neovascularisation. The treatment trial included 49 PEDs within $1500 \mu \mathrm{m}$ of the foveal centre in patients aged $50-80$ years. Of these all but four involved the centre of the fovea. The trial had excluded eyes with clear evidence of subretinal new vessels using the following criteria: the presence of visible new vessels on angiography, haemorrhages, and exudates. Eyes randomly assigned to laser treatment had treatment repeated at 2 week intervals up to three times until the detachment flattened or new vessels were detected. Follow up visits were scheduled every 3 months during the first year of the trial and again at 18 months. After suspension of the trial patients were asked to return at 2 years, and yearly thereafter. Visual acuity, morphological appearance, fundus photographs, and fluorescein angiograms were assessed at each visit.

Of the 49 patients recruited into the treatment trial, we excluded from our review two who died before the 6 month visit and one who was lost to follow up before the 18 month visit. Another four photographic files could not be located. The entry angiograms of 42 eyes in 42 patients remained for assessment.

The entry stereoangiograms were reviewed by three observers who were masked from the final outcome and from each other's assessments. Entry angiograms were evaluated for the presence or absence of subpigment epithelial neovascularisation; every effort was made to designate a lesion to either category although 
some lesions proved unclassifiable. Subpigment epithelial neovascularisation was considered to be present if the following features were found: haemorrhage, exudate, irregular fluorescence, early and pronounced hyperfluorescence at the edge of the lesion, a notch, and irregular hyperfluorescence beyond the edge of a lesion which was usually at the site of a notch.

The predictive value of each observer's assessments was determined by comparing the original classification with the morphological outcome during review. The development of new vessels during the period of review was shown by the presence of subretinal haemorrhage, exudates, or frank subretinal neovascularisation (fibrovascular disciform scar or leaking subretinal capillary plexus). A PED which showed no evidence of neovascularisation, whether it flattened spontaneously with or without atrophy, ripped, stayed unchanged, or developed geographic atrophy, was considered to have an avascular outcome.

Because the correlation of the initial classification and subsequent outcome was the same whether or not the lesion was treated the results have been analysed as a single population.

\section{Results}

Data were available on 42 patients up to 18 months, 38 patients to 2 years, and 34 patients to 4 years. Of the eight patients who missed the 4 year visit four had vascular outcomes manifested by haemorrhagic disciform lesions at an earlier visit. Of the remaining four patients, two remained avascular at 1.5 years and two at 2 years.

- The specificity for correct prediction of vascular or avascular outcome was $78 \%, 80 \%$, and $89 \%$ and the sensitivity $74 \%, 79 \%$, and $79 \%$ for observers 1,2 , and 3 respectively (Table 1 ). No classification was given by the three observers in $3 \%, 5 \%$, and $12 \%$ of cases.

Full agreement was reached in only 23 eyes $(55 \%), 10$ of which were classified as vascular and 13 as avascular; both groups contained treated and untreated patients. All 10 eyes identified by each observer as 'vascular' subsequently developed undoubted evidence of subretinal neovascularisation. Of the 13 eyes designated as avascular by all three observers only one developed subretinal neovascularisation and this occurred after the 4 year visit.

\section{Discussion}

The correlation between the designation of the lesion at entry to trial and the subsequent outcome of PEDs using ophthalmoscopic and

Table 1 Comparison of classification and subsequent outcome of lesion

\begin{tabular}{|c|c|c|c|c|c|c|c|c|c|}
\hline & \multicolumn{3}{|c|}{ Entry assessment $(n=42)$} & \multicolumn{3}{|c|}{ Specificity } & \multicolumn{3}{|c|}{ Sensitivity } \\
\hline & Vasc & Avasc & $?$ & Vasc & Avasc & Overall & Vasc & Avasc & Overall \\
\hline $\begin{array}{l}1 \\
2 \\
3\end{array}$ & $\begin{array}{l}16 \\
19 \\
22\end{array}$ & $\begin{array}{l}24 \\
22 \\
15\end{array}$ & $\begin{array}{l}2 \\
1 \\
5\end{array}$ & $\begin{array}{l}14 / 16 \\
16 / 19 \\
19 / 22\end{array}$ & $\begin{array}{l}17 / 24 \\
17 / 22 \\
14 / 15\end{array}$ & $\begin{array}{l}31 / 40(78 \%) \\
33 / 41(80 \%) \\
33 / 37(89 \%)\end{array}$ & $\begin{array}{l}14 / 23 \\
16 / 23 \\
19 / 23\end{array}$ & $\begin{array}{l}17 / 19 \\
17 / 19 \\
14 / 19\end{array}$ & $\begin{array}{l}31 / 42(74 \%) \\
33 / 42(79 \%) \\
33 / 42(79 \%)\end{array}$ \\
\hline
\end{tabular}

Vasc $=$ vascular PEDs.

Avasc $=$ avascular PEDs.

$?=$ cases in which no definite prediction could be made. angiographic clues supports the validity of the criteria used in this study to indicate the presence of subpigment epithelial new vessels. There was close but not perfect parity between the three observers for specificity and sensitivity. Particularly noteworthy was the good correlation between those classified as vascular and the subsequent behaviour of the lesion. However from the lack of agreement between observers it is evident that the interpretation of clinical signs is imprecise. Of the criteria used the significance of uneven filling and marginal hyperfluorescence were the most difficult to assess, while the presence of notches was relatively easy to recognise. This inconsistency might be avoided with the use of standardised photographs which define each clue although the interpretation of fluorescein angiograms is imprecise. For instance irregular hyperfluorescence within a PED or in the adjacent retina may signal the presence of occult new vessels but may also be due to uneven binding of dye in Bruch's membrane and detached tissues or to irregular blockage of fluorescence by pigment in the detached pigment epithelium. The pigment may be blood or melanin which can be seen ophthalmoscopically or lipofuscin which cannot be detected. It was lesions with uneven filling that accounted for most disagreement between the three observers and for the undesignated cases. The best specificity scores were achieved by the observer with the largest number of cases which were unclassified.

More encouraging is the fact that only one case of the 23 with unanimous designation behaved in a way different from that predicted whether or not the lesion was treated. The single exception did not have undoubted evidence of neovascularisation until more than 4 years of review. This indicates that the clinical clues are valid predictors of subsequent behaviour of the lesion. These data also imply that whatever effect photocoagulation had upon the lesion, it did not seem to influence the incidence of detectable neovascularisation.

It is surprising that the ability to predict the long term outcome was so good albeit in only a few cases. It appears that a lesion which has no features of new vessels is unlikely to develop detectable new vessels during the evolution of the lesion. The designation of a lesion as avascular during the period of assessment does not prove that new vessels did not exist in the subretinal space at any time since there is evidence they may resolve spontaneously ${ }^{32}$ or remain unseen. If cases existed with subpigment epithelial new vessels which were not indicated by angiography the blood vessels did not appear to alter the course of the disorder.

These observations show that vascular or avascular evolution of PEDs could be predicted with some accuracy using the clinical signs believed to imply the presence of subpigment epithelial new vessels. Agreement among the three observers further reduced the probability of error. Since the prognosis and possible new therapeutic approaches may differ for vascular and avascular PEDs the ability to detect new vessels reliably might promote the development of more effective therapeutic methods. 
S Pagliarini is supported by British Council Grant ITA/2281/199.

1 Gass JDM, Norton EWD, Justice J. Serous detachment of the retinal pigment epithelium. Trans Am Acad Ophthalmol retinal pigment epithelium. Trangol 1966; 70: $990-1015$.

2 Gass JDM. Pathogenesis of disciform detachment of the neuroepithelium. III. Senile disiform macular degeneration. Am f Ophthalmol 1967; 63: 617-44.

3 Teeters VW, Bird AC. A clinical study of the vascularity of senile disiform macular degeneration. Am $\mathcal{f}$ Ophthalmol 1973; 75: 53-65.

4 Teeters VW, Bird AC. The development of neovascularization of senile disciform macular degeneration. Am $\mathcal{F}$ Ophthalmol 1973; 76: 1-18

5 Gass JDM. Serous retinal pigment epithelial detachment with a notch. A sign of occult choroidal neovascularization. Retina 1984; 4: 205-20.

6 Gass JDM. Pathogenesis of disciform detachment of the neuroepithelium. IV Fluorescein angiographic study of senile disiform macular degeneration. Am $\mathcal{f}$ Ophthalmol 1967; 63: 645-59.

7 Gass JDM. Stereoscopic atlas of macular disease. Diagnosis and treatment. 3 ed. St Louis: Mosby, 1987: 789.

8 Bird AC, Marshall J. Retinal pigment epithelial detachments in the elderly. Trans Ophthalmol Soc UK 1986; 105: 674-82. 9 Sarks SH. New vessel formation Soc UK 1986; 105: 674-82.

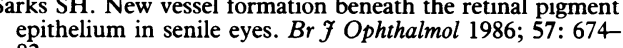
82 .

10 Green WR, Key SN III. Senile macular degeneration: a histopathologic study. Trans Am Opthalmol Soc 1977; 75: $180-254$.

11 Gass JDM. Drusen and disciform macular detachment and degeneration. Arch Ophthalmol 1973; 90: 206-17.

12 Chandra SR, Gragoudas ES, Friedman E, Van Buskirk EM, Klein ML. Natural history of disciform degeneration of the macular. Am f Ophthalmol 1974; 78: 579-82.

13 Gregor Z, Bird AC, Chisholm IH. Senile disciform macular degeneration in the second eye. Br 7 Ophthalmol 1977; 61: degen

14 Lewis ML. Idiopathic serous detachment of the retinal pigment epithelium. Arch Ophthalmol 1978;96:620-4.

15 Meredith TA, Braley RE, Aaberg TM. Natural history of serous detachments of the retinal pigment epithelium. Am $\mathcal{F}$ Ophthalmol 1979; 88: 643-51.

16 Braunstein RA, Gass JDM. Serous detachments of the retinal pigment epithelium in patients with senile macular disease. Am f Ophthalmol 1979; 88: 652-60.
17 Klein ML, Obertynski H, Patz A, Fine SL, Kini M. Followup study of detachment of the retinal pigment epithelium. up study of detachment of the retin

18 Casswell AG, Kohen D, Bird AC. Retinal pigment epithelial detachments in the elderly: classification and outcome. $\mathrm{Brf}$ detachments in the elderly: classil

19 Poliner LS, Olk RJ, Burgess D, Gordon ME. Natural history of retinal pigment epithelial detachments in age-related macular degeneration. Ophthalmology 1986; 93: 543-50.

20 Elman MJ, Fine SL, Murphy RP, Patz A, Auer C. The natural history of serous retinal pigment epithelium detachment in patients with age-related macular degeneration. Ophthalmology 1986; 93: 224-30.

21 Hoskin A, Bird AC, Sehmi K. Tears of detached retinal pigment epithelium. Brf Ophthalmol 1981; 65: 417-22.

22 Chuang EL, Bird AC. The pathogenesis of tears of the retinal pigment epithelium. Am $\mathcal{f}$ Ophthalmol 188; 105: 285-90.

23 Schatz H, Patz A. Exudative senile maculopathy. I. Results of argon laser treatment. Arch Ophthalmol 1973; 90: 183-96.

24 Bird AC. Recent advances in the treatment of senile disciform macular degeneration of photocoagulation. Brf Ophthalmol macular degeneration

25 Bird AC. Macular disciform response and laser treatment. Trans Ophthalmol Soc UK 1977; 97: 490-3.

26 The Moorfields Macular Study Group. Retinal pigment epithelial detachments in the elderly: a controlled trial of argon laser photocoagulation. $\mathrm{Br} \mathcal{F}$ Ophthalmol 1981; 66: $1-16$

27 Ho PC, Namperumalsamy P, Pruett RC. Photocoagulation of serous detachments of the retinal pigment epithelium in patients with senile macular disease. Ann Ophthalmol 1984; 16: 213-8.

28 Singerman LJ. Laser photocoagulation for choroidal new vessel membrane complicating age-related macular degeneration associated with pigment epithelial detachment. Retina 1988; 8: 111-21.

29 Bressler NM, Bressler SB, Fine SL. Age-related macular degeneration. Surv Ophthalmol 1988; 32: 375-413.

30 Soubrane G, Coscas G, Koenig F, Francais C. Natural history of occult forms of SRNV. Doc Ophthalmol Proc Series 1987; of occult form.

31 Barondes MJ, Pagliarini S, Chisholm IH, Hamilton AM, Bird AC. Controlled trial of laser photocoagulation of pigment epithelial detachments in the elderly; a four year review. Br F Ophthalmol 1992; 76: 5-7.

32 Miller H, Miller B, Ryan SL. The role of retinal pigment epithelium in the involution of subretinal neovascularization. Invest Ophthalmol Vis Sci 1986; 27: 1644-52. 